\title{
European CDS Premiums and Industrial Production
}

\author{
Lechner Gerhard, Vogl Dieter \\ FH JOANNEUM, University of Applied Sciences, Graz, Austria
}

\begin{abstract}
This paper aims to find the dependence of the important European corporate CDS (Credit Default Swaps) indices and some selected country CDS of industrial production. While the existing literature acknowledges the importance of macroeconomic factors in determining CDS spreads from a general perspective, the importance of economic growth for individual firms, banks, and countries has not been examined in detail. The main hypothesis of the paper claims that weaker ratings are more growth-sensitive than better ratings. This means that the CDS will react more strongly to the industrial production when the rating is weaker. The authors analyzed the European CDS indices of investment grade, high yield enterprises, senior bank debt, and subordinated bank debt with a linear OLS (Ordinary Least Squares) regression. While the authors had to reject their main hypothesis for the European indices, they could prove their hypothesis concerning the country perspective: The German CDS has the weakest relation to industrial output, and the authors' hypothesis can be confirmed tendentially concerning the correlations of the more weakly rated countries (European periphery), which are much better. Surprisingly the correlation between peripheral country CDS and industrial production is much stronger than the correlation of corporate and bank CDS and industrial production.
\end{abstract}

Keywords: industrial production, European credit default swaps, determinant of CDS

The market of Credit Default Swaps (CDS) increased enormously until 2008. The traded volume reached its peak of about 60 trillions of USD (Deutsche Bank Research, 2010) in 2008 but then dropped down to approximately 15 trillions of USD in May 2016 (ISDA Swapsinfo, 2016). This huge reduction of approximately $75 \%$ of traded volume may be correlated with the rising regulatory frameworks within the banking industry. CDS are widely used to reduce credit risks of countries, banks, or enterprises in general and are moreover considered for hedging speculative activities. In contrast to corporate bonds, the market of CDS shows much more liquidity and CDS are declared in basis points and not in total return ratios as seen in bond markets.

Recent scientific studies have been carried out to identify influential factors for CDS markets. Guo and Newton (2013) found a multi-correlation among volatility, leverage, liquidity, risk free interest rate, and CDS premiums. These correlations have been identified empirically, based on the so-called "pioneering model of Merton (1974)" (Collin-Dufresne, Goldstein, \& Martin, 2001; Zhang, 2008; Zhang, Zhou, \& Zhu, 2009; Ericsson, Jacobs, \& Oviedo, 2009; Z. D. Zhong, Cao, \& Z. Zhong, 2010). Additionally, Abid and Naifar (2006) showed the significant influence of credit rating, maturity, and slope of the yield curve on CDS premiums. In

Corresponding author: Gerhard Lechner, Ph.D., lecturer, Department of Management, Institute of Banking and Insurance, FH JOANNEUM, University of Applied Sciences, Graz, Austria; research fields: international financial markets, financial economics, monetary policy, alternative investments, ethical banking, and history of economic theory.

Dieter Vogl, Ph.D., head of the Institute of Banking and Insurance, Department of Management, FH JOANNEUM, University of Applied Sciences, Graz, Austria; research fields: mathematics, international financial markets, econometrics. 
empirical studies, Blanco, Brennan, and Marsh (2005) found out that the volatility of equities and the rating show much more influence on CDS premiums than on the return of corporate bonds. Lahiani, Hammoudeh, and Gupta (2016) identified a non-linear correlation among prices of assets, energy, federal funds rate, and CDS premiums. Chiaramonte and Casu (2013) investigated the determinants for bank CDS but did not go into the relationship of real economic variables.

Less research has been done to find the relationship between economic growth and CDS premiums. Tang and Yan (2010) were the first authors to investigate this relationship. Tang and Yang found a negative relationship between economic growth and CDS premiums, which means that stronger economic volatility leads to higher CDS premiums.

At the same time, similar research was carried out by Baum and Wan (2010), who also wanted to find out the influence of macroeconomic volatility on the CDS premiums of numerous corporates. The authors defined macroeconomic volatility through the variance of GDP growth, industrial production, and the monthly yields of the S\&P 500. They interpolated the quarterly GDP with the industrial production data to monthly figures (Baum \& Wan, 2010, pp. 1164-1165). It has to be noted, though, that Baum and Wan do not provide information regarding the country or region for which they used the GDP growth rate and industrial production. They showed a clear significant influence of macroeconomic volatility and CDS premiums. Baum and Wan could identify the statistical relationship for companies up to the BBB rating but only a less pronounced relationship for companies with a high yield grade (Baum \& Wan, 2010, pp. 1169-1170).

Baum and Wan (2010) used data for the period of 2001-2006, whereas Tang and Yan (2010) took data for the period of 1999-2006. The results of both studies were confirmed by Kajurova (2015), who claimed that the influential factors differ according to several market conditions. Kajurova (2015) did not consider industrial production and GDP growth as factors of influence for CDS premiums but pointed out that macroeconomic volatility is defined as an implicit volatility of financial markets (Kajurova, 2015, p. 1115). The advantage of Kujurova's study lies in the fact that she examined more periods, namely the pre-crisis period, the crisis period (2008/2009), and the post-crisis period.

Other studies discussing the economic growth and CDS include Yuang and Pongsiri (2015) and Kim, Salem, and $\mathrm{Wu}$ (2015). They reported an influence of macroeconomic variables and macroeconomic news on CDS premiums. Yuang and Pongsiri (2015) investigated the influence of fiscal policy and economic prospects on sovereign European CDS. Economic growth is understood as a mix of econometric variables. The future GDP is a variable influencing sovereign CDS. Yuang and Pongsiri (2015) indicated the influences of fiscal deficits on CDS (see Yuang \& Pongsiri, 2015, pp. 67-70). Kim et al. (2015) moreover found evidence that macroeconomic news influence sovereign CDS.

Some studies focus on the influence of the financial crisis on the correlation of growth rate and CDS. In a detailed analysis, Kalbaska and Gatkowski (2012) showed that correlations between countries before the so-called financial crisis are generally less pronounced than after the crisis. Correlation figures of CDS premiums of Germany compared to European countries with ratings lower than BBB are less pronounced after 2009 than correlation figures of CDS among the countries with a rating of less than BBB (Kalbaska \& Gatkowski, 2012, p. 664).

More analyses of CDS of European countries can be found, for instance, in the studies of Alter and Schüler (2011; 2012), Aizenmann, Hutchison, and Jinjarak (2011), Archaya, Drechsler, and Schnabl (2011), Dieckmann and Planck (2011), and Ejsing and Lemke (2009), but those studies did not concentrate on the relation between industrial production and CDS. 
In this paper, the authors concentrate on the influence of European countries, banks, and corporates with respect to CDS premiums within the time period of October 2011 to February 2016. The authors define the growth of industrial production as an economic development. The aim of the paper is to extend and add to the above mentioned studies with current data. In addition, the authors want to show that premiums of CDS in peripheral countries, like Spain, Portugal, or Cyprus, are more growth-sensitive than the CDS premiums from Germany. The same can be seen as true for bank and corporate CDS. A higher default risk means that the CDS premium should be more growth-sensitive than a corporate with a lower default risk. For example, subordinated bank CDS and high yield corporates should react more sensitively to industrial production, which means that the correlation is stronger than for senior bank CDS or investment grade CDS. The authors calculate the correlations by using a linear OLS (Ordinary Least Squares) regression.

\section{Methodology and Data}

In the authors' study, they use a time series from Bloomberg in a monthly resolution from October 2011 to February 2016 to show a correlation between industrial production and CDS premiums. The authors took into account the yearly growth rates of industrial production. From the country perspective, the authors used 17 countries of the Eurozone with different investment grade ratings (see Table 1). Additionally, European CDS indices for investment as well as high yield grade were used, and senior and subordinated bonds of banks were considered. The authors used 5-year CDS for all countries and corporates. Table 1 summarizes the rating of the chosen countries.

Table 1

Rating for European Countries

\begin{tabular}{llll}
\hline & S\&P & Moody's & Fitch \\
\hline Germany & AAA & Aaa & AAA \\
Finland & AA+ & Aaa & AA+ \\
Austria & AA+ & Aaa & AA+ \\
France & AA & Aa2 & AA \\
Belgium & AA & Aa3 & AA \\
Estonia & AA- & A1 & A+ \\
Ireland & A+ & A3 & A \\
Slovakia & A+ & A2 & A+ \\
Slovenia & A- & Baa3 & BBB + \\
Spain & BBB + & Baa2 & BBB + \\
Italy & BBB- & Baa2 & BBB + \\
Portugal & BB + & Ba1 & BB + \\
Cyprus & BB- & B1 & B + \\
\hline
\end{tabular}

The authors can therefore prove that CDS of countries with a minor rating are more growth-sensitive than the CDS of countries with a higher rating. The relationship is negative, which means that higher industrial growth (year after year) leads to a lower CDS. For corporate and bank CDS, the relationship is the same: The higher industrial production is, the lower the various CDS are.

The authors use a linear regression with a $99 \%$ confidence level to prove their hypothesis of weaker ratings being more growth-sensitive than better ratings, where industrial production, IP, is the independent variable and the CDS is the dependent variable. 


$$
C D S_{t}=\alpha+\beta I P \mathrm{t}-1+\varepsilon
$$

Parameters are given by the theory of linear regression.

\section{Econometric Analysis of Data}

The econometric analysis presented below is divided into two parts: first, a country analysis; and second, a corporate analysis.

\section{Data Analysis European Sovereign CDS Market}

The authors first investigate the annual change of the European industrial production with respect to the level of the corresponding 5-year CDS. The data of industrial production and CDS show a time lag of one month, as indicated in equation (1). This lag arises as a consequence of the time release of the data, i.e. data of industrial production are released within the fifth and tenth day of the subsequent month.

The authors performed a linear regression taking into account the $99 \%$ confidence interval and found a strong correlation between European industrial production and CDS premiums. Table 2 summarizes the results. Countries with ratings of BBB and below show a more pronounced correlation between industrial production and CDS premiums. Surprisingly, Portugal has a correlation similar to Germany. However, as Cyprus, Spain, Italy, and Slovenia have the highest correlations, the authors' hypothesis of weaker ratings being more growth-sensitive than better ratings is tendentially supported by the data analysis.

Table 2

Linear Regression Country CDS and European Industrial Production

\begin{tabular}{lllll}
\hline Regression results & Correlation & T-stat & P-value & Adj. $\mathrm{R}^{2}$ \\
\hline Germany & -0.69 & -6.85 & 0.000 & 0.47 \\
Finland & -0.70 & -6.89 & 0.000 & 0.48 \\
Austria & -0.58 & -5.02 & 0.017 & 0.32 \\
France & -0.70 & -7.03 & 0.001 & 0.49 \\
Belgium & -0.58 & -5.03 & 0.016 & 0.32 \\
Estonia & -0.64 & -5.92 & 0.003 & 0.40 \\
Ireland & -0.71 & -7.17 & 0.000 & 0.50 \\
Slovakia & -0.73 & -7.50 & 0.000 & 0.52 \\
Slovenia & -0.79 & -9.11 & 0.000 & 0.62 \\
Spain & -0.86 & -12.37 & 0.000 & 0.74 \\
Italy & -0.80 & -9.52 & 0.000 & 0.63 \\
Portugal & -0.67 & -6.44 & 0.001 & 0.44 \\
Cyprus & -0.83 & -10.79 & 0.000 & 0.69 \\
\hline
\end{tabular}

For the authors, it was also an interesting question whether the correlations improve when they take the industrial production data of the several countries as the independent variable. Normally, the relationship should improve. Table 3 summarizes the results and shows a slight increase of the correlations for peripheral countries (with the exception of Italy). The strongest drop in the correlation values is given for Germany approaching practically the value of zero, which means that no correlation can be derived.

When these results are compared to those shown in Table 2, Spain surprisingly has the strongest correlation, whereas Portugal and Cyprus show fewer effects of the correlation. In comparison to the results of Table 2, the authors' hypothesis of weaker ratings being more growth-sensitive than better ratings can be supported better with the industrial production data of several countries. On the one hand, there is no 
correlation for the high grade countries like Germany, Finland, and Austria. On the other hand, lower graded countries have relatively high negative correlations.

Compared to the studies of Yuang and Pongsiri (2015), the authors could show that lower rated countries are more growth-sensitive than high grade countries. Nevertheless, it has to be noted that the authors have an autocorrelation, and therefore the validity of the results is limited.

Table 3

Linear Regression Country CDS With Country Specific Industrial Production

\begin{tabular}{lllll}
\hline Regression results & Correlation & T-stat & P-value & Adj. $\mathrm{R}^{2}$ \\
\hline Germany & -0.10 & 0.71 & 0.470 & -0.01 \\
Finland & 0.02 & 0.12 & 0.909 & -0.02 \\
Austria & 0.36 & 2.72 & 0.009 & 0.11 \\
France & -0.27 & -2.04 & 0.046 & 0.06 \\
Belgium & -0.34 & -2.59 & 0.013 & 0.32 \\
Estonia & -0.65 & -6.11 & 0.001 & 0.41 \\
Ireland & -0.45 & -3.59 & 0.001 & 0.19 \\
Slovakia & -0.05 & -0.37 & 0.715 & -0.02 \\
Slovenia & -0.23 & -1.70 & 0.095 & 0.03 \\
Italy & -0.70 & -7.21 & 0.000 & 0.49 \\
Spain & -0.86 & -12.80 & 0.000 & 0.75 \\
Cyprus & -0.82 & -10.43 & 0.000 & 0.67 \\
Portugal & -0.65 & -6.13 & 0.001 & 0.41 \\
\hline
\end{tabular}

\section{Data Analysis of Corporate and Bank CDS}

Table 4 (below) shows that the correlations between the European industrial production and banking and corporate CDS are quite similar to the ones described above. For the confidence level of $99 \%$, all p-values show significant values. The authors' hypothesis of weaker ratings being more growth-sensitive than better ratings has to be rejected because bank senior CDS have a better correlation than bank subordinated CDS. Concerning the corporate CDS, the correlation between high yield and investment grade is approximately the same.

Table 4

Linear Regression Results for Corporate and Bank CDS

\begin{tabular}{lllll}
\hline Regression results & Correlation & T-stat & P-value & Adj. R $^{2}$ \\
\hline Bank senior & -0.68 & -6.64 & 0.001 & 0.45 \\
Bank subordinated & -0.63 & -5.89 & 0,003 & 0.38 \\
Corporate IG & -0.67 & -6.47 & 0.001 & 0.43 \\
Corporate HY & -0.67 & -6.49 & 0.001 & 0.44 \\
\hline
\end{tabular}

The analysis could be extended: It would be interesting to calculate the correlations between the industrial production of the countries and the bank and corporate CDS of the various European countries. The correlations should be better for banks and corporates from countries with a weak rating. This assumption is based on Alter and Schüler (2011; 2012) and Avino and Cotter (2014). Alter and Schüler (2011; 2012) claimed that the CDS of banks follow the sovereign CDS. However, their analysis was based on older data. The study of Avino and Cotter (2014) showed with data from the time period of 2004-2013 that bank CDS from Germany and Sweden strongly affect the development of sovereign CDS, whereas CDS from countries like Portugal or Cyprus are strongly influenced by sovereign CDS. 


\section{Conclusions}

First and foremost, it has to be pointed out that the validity of the data is limited. The period under review is also relatively short, but this is not unusual for CDS research. In the authors' analysis, they could show that especially sovereign CDS are strongly correlated with industrial production. The authors' main contribution to research is that they could demonstrate that European peripheral sovereign CDS are better correlated with industrial production than Germany and the other core countries (from 2011-2016). The best correlation was for Spain.

The initial hypothesis claimed that countries and corporates with a lower rating were more growth-sensitive than countries and corporates with a better rating. While initial hypothesis is not completely in line with the results, there is the tendency for the hypothesis to be true. The hypothesis fits better for CDS premiums and the national industrial production.

Concerning the European industrial production, there are good correlations for all countries. For the core countries, the authors would have expected a much weaker relationship than the results indicated. This could mean that the CDS premiums were more dependent on the global economic development than on the national development. Probably the European debt crisis of 2011-2012 made the core countries more sensitive to the European and global growth perspective.

The authors' results add to the many studies investigating the macroeconomic influences on CDS demonstrating the relationship between economic growth and sovereign CDS. Apart from economic growth, also other macroeconomic variables, such as money market and equity volatility, have an impact on sovereign CDS. Especially during the financial crisis, the relationship between market volatility and CDS was much higher than that of industrial production and CDS. The crisis started on the financial market and affected the real economy later. From 2011 to 2016, the relationship between industrial production and sovereign CDS is much stronger than during the crisis period. Apart from budgetary problems, economic growth is an important factor, especially for the peripheral countries.

Concerning the relationship between European corporate and bank CDS, the authors' hypothesis of weaker ratings being more growth-sensitive than better ratings could not be confirmed. Contrary to the work of Baum and Wan (2010), the authors' linear model for high yield CDS is significant, but the correlation of the investment grade CDS with industrial production is almost the same as for high yield CDS, which contradicts their hypothesis. However, the factor of industrial production in general explains well the CDS of the corporates. Many studies have already shown this relationship.

Concerning bank CDS, the authors also had to reject their hypothesis because the correlation between subordinated bank CDS and industrial production is weaker than that for senior bank CDS. It would be interesting to make a more detailed analysis of bank CDS, for example for different countries. The relationship is supposed to be better for peripheral banks than for core country banks.

\section{References}

Abid, F., \& Naifar, N. (2006). The determinants of credit default swap rates: An explanatory study. International Journal of Theoretical and Applied Finance, 9(1), 23-42.

Acharya, V. V., Drechsler, I., \& Schnabl, P. (2011). A pyrrhic victory? Bank bailouts and sovereign credit risk. Working Paper.

Aizenman, J., Hutchison, M., \& Jinjarak, Y. (2011). What is the risk of European sovereign debt defaults? Fiscal space, CDS spreads and market pricing of risk. NBER Working Paper Series. (Vol. 17407). 
Alter, A., \& Schüler, Y. S. (2011). Credit spread interdependencies of European states and banks during the financial crisis. Working Paper.

Alter, A., \& Schüler, Y. S. (2012). Credit spread interdependencies of European states and banks during the financial crisis. Journal of Banking \& Finance, 36, 3444-3468.

Avino, D., \& Cotter, J. (2014). Sovereign and bank CDS spreads: Two sides of the same coin? Journal of International Financial Markets, Institutions and Money, 32, 72-85.

Baum, C. F., \& Wan, C. (2010). Macroeconomic uncertainty and credit default swap spreads. Journal of Applied Financial Economics, 20, 1163-1171.

Blanco, R., Brennan, S., \& Marsh, I. W. (2005). An empirical analysis of the dynamic relation between investment-grade bonds and credit default swaps. Journal of Finance, 60, 2255-2281.

Chiaramonte, L., \& Casu, B. (2013). The determinants of bank CDS spreads: Evidence from the financial crisis. European Journal of Finance, 13(9), 861-887.

Collin-Dufresne, P., Goldstein, R. S., \& Martin, J. S. (2001). The determinants of credit spread changes. Journal of Finance, 56, 2177-2207.

Deutsche Bank Research. (2010). Credit default swaps-Auf dem weg zu einem robusten system (Credit default swaps-On the path to a robust system). Retrieved from https://www.dbresearch.de/PROD/DBR_INTERNET_DE-PROD/PROD000000 0000254634/Credit_Default_Swaps\%3A_Auf_dem_Weg_zu_einem_robuste.PDF

Dieckmann, S., \& Plank, T. (2011). Default risk of advanced economies: An empirical analysis of credit default swaps during the financial crisis. Review of Finance. Retrieved from http://dx.doi.org/10.1093/rof/rfr015

Ejsing, J. W., \& Lemke, W. (2009). The Janus-headed salvation: Sovereign and bank credit risk premia during 2008-2009. ECB Working Paper 1127.

Ericsson, J., Jacobs, K., \& Oviedo, R. (2009). The determinants of credit default swap premia. Journal of Financial and Quantitative Analysis, 44, 109-132.

Guo, B., \& Newton, D. (2013). Regime-Dependent liquidity determinants of credit default swap spread changes. The Journal of Financial Research, 36(2), 279-298.

ISDA Swapsinfo. (2016). Trading volume CDS. Retrieved from http://www.swapsinfo.org/charts/swaps/notional-outstanding

Kajurova, V. (2015). What determined CDS spreads of the UK financial institutions? Procedia Economics and Finance, 26, $1113-1118$.

Kalbaska, A., \& Gatkowski, M. (2012). Eurozone sovereign contagion-Evidence from the CDS market (2005-2010). Journal of Economic Behavior \& Organization, 83, 657-673.

Kim, S. J., Salem, L., \& Wu, E. (2015). The role of macroeconomic news in sovereign CDS markets: Domestic and spillover news effects from the U.S., the Eurozone and China. Journal of Financial Stability, 18, 208-224.

Lahiani, A., Hammoudeh, S., \& Gupta, R. (2016). Linkages between financial sector CDS spreads and macroeconomic influence in a nonlinear setting. International Review of Economics and Finance, 43, 443-456.

Merton, R. C. (1974). Pricing of corporate debt—Risk structure of interest rates. Journal of Finance, 29, 449-470.

Tang, D. Y., \& Yan, H. (2010). Market conditions, default rates and credit spreads. Journal of Banking and Finance, 34, $743-753$.

Yuang, C., \& Pongsiri, T. J. (2015). Fiscal austerity, growth prospects, and sovereign CDS spreads: The Eurozone and beyond. International Economics, 141, 50-79.

Zhang, B. Y., Zhou, H., \& Zhu, H. (2009). Explaining credit default swap spreads with the equity volatility and jump risks of individual firms. Review of Financial Studies, 22, 5099-5131.

Zhang, F. X. (2008). Market expectations and default risk premium in credit default swap prices: A study of Argentine default. Journal of Fixed Income, 18, 37-55.

Zhong, Z. D., Cao, C., \& Zhong, Z. (2010). The information content of option-implied volatility for credit default swap valuation. Journal of Financial Markets, 13, 321-343. 